\title{
Institutional Transformation of the Socioeconomic System Under the Impact of Digitalization Processes
}

\author{
Vera Nikiforova \\ Department of Economics and Finance \\ Financial University under the Government of the Russian \\ Federation (Moscow), St. Petersburg Branch \\ St. Petersburg, Russia \\ VDNikiforova@fa.ru \\ Viktor Vasilyonok \\ Faculty of Technological Management and Innovations \\ ITMO University \\ St. Petersburg, Russia \\ fem1421@yandex.ru
}

\author{
Irina Sergeeva \\ Faculty of Technological Management and Innovations \\ ITMO University \\ St. Petersburg, Russia \\ igsergeeva@gmail.com
}

\author{
Aleksandr Nikiforov \\ Department of Economics and Finance \\ Financial University under the Government of the Russian \\ Federation (Moscow), St. Petersburg Branch \\ St. Petersburg, Russia \\ AANikiforov@fa.ru
}

\begin{abstract}
The paper analyzed the processes of creating new institutions and transforming the activity of the existing institutions under the impact of digitalization in the time of economic instability and sociopolitical risks and threats. The authors consider different scientific views of public and intercountry regulation of the widespread introduction of digital technology into the global and national economies. In this context, such a matter is considered as the "trust-responsibility" combination in smart contracts and other agreements of a new type, which embrace the interaction of human and non-human subjects as an integral whole. The aim of the article is to theoretically understand the transformation processes of legal institutions from the position of qualitative analysis of the change in socioeconomic relationships, develop conclusions and recommendations for the effective use of modern methods, approaches and tools of regulation so that not only economic stability but also economic growth is ensured.
\end{abstract}

Keywords: information technology, economic regulation, trust and liability institutions, factors of influence on the socioeconomic sphere

\section{INTRODUCTION}

Today globalization and informatization are the dominant factors of evolutionary development of human society. They are interrelated and can make a significant impact on social, economic, political, cultural and other aspects of social life. Many various opinions on the content and nature of the influence that technological changes have on the globalizing economies make this problem even more controversial.
It should be noted that scientific research is mostly presented by empirical analysis. So far there have been no concepts which would be generally recognized and confirmed in practice, not limited to empirical generalizations and statistics but instead could give a comprehensive explanation to the processes of spreading new technologies and their impact on the socioeconomic life of society, and would make it possible to project the effects of life-changing circumstances in the socioeconomic sphere. $[1,2]$

Today the attention of researchers focuses on considering multi-purpose digital technology not only in terms of introducing it into economy, education, culture, and other spheres of social life, but also in terms of considering it an institutional technology, which is based on algorithmic trust, new civil public and collective institutions aimed at solving the problems of employment, inequality, political power, legislative control, etc. $[3,4]$.

\section{MATERIALS AND METHODS}

It has to be accepted that information technology brings changes into how the concepts of "trust" and "liability" are traditionally understood, makes us reject some conventions and consider people (users) together with software complexes as independent and, probably, equal acting units of socioeconomic relations. Such an approach makes the actuarial-network theory most suitable for getting ideas about liability and trust in economic sectors, financial sphere and other aspects of social life, oriented on using digital technology. 
The following ones can be mentioned among breakthrough

Growing instability and risk due to new global risks, threats and challenges, including the ones related to digitalization, are preconditioned by the development of modern human society. These are the risks of increasing unemployment, socioeconomic instability, a growing gap in the levels of technological development between countries, increasing probability of man-made disasters, growth in terrorism, disclosure of confidential information, as well as threats of reduced economic security, growing inequality between different groups of people inside a country by the level of intellectual resources they use, etc. [5] It has to be understood that many of the above risks cannot be avoided with the help of the available socioeconomic experience and legal institutions.

Several dozens of thousands of new institutions, organizations and enterprises, having an international or global nature (including multinational and transnational financial corporations and organizations) work side by side with the well-established ones. Dealing with the problem of instability of the world economy, in particular, the world currency system, markets of currency, credit, stock, and gold, their activity includes unification of standards, norms and rules applied to the global regulation of economy and financial markets relying on single principles. The standards, principles and directives developed by international structures are sooner or later introduced into the national regulative system at least to a certain degree: Basel capital adequacy ratio of the Bank for International Settlements, the principles of corporate management of the OECD, principles of anti-money laundering, international accounting standards, etc.

Taking up more and more important positions among the economic factors creating value added, digitalization, in turn, can give additional momentum to the economy and financial sphere. Jointly with the development of network relationships, it can also create a new type of competition - intra-network competition due to forming new conditions for cooperation of companies and attraction of customers. In these conditions companies and branches tend to return from the countries with cheap manpower into the developed countries, closer to the end user. There is also change in supply and demand, with new needs and capabilities being created. According to some estimates, today, technological capabilities of data storing, transferring, and processing are constantly growing, and, in the context of the global economy, this growth will be exponential. [6]

\section{RESULTS AND DISCUSSION}

In Russia, digitalization and new knowledge are, predominantly, the prerogative of large business. Medium and small business frequently reacts to the technological changes by subsequent improvement of the existing processes with the use of digital technologies, and it is more inclined to digital adaptation. By and large, digitalization in the country is based on the main trends of the third and fourth industrial revolutions. Gradually, the regulatory provision of digitalization processes is forming, the education system is being rebuilt, and the main infrastructural elements of society (information infrastructure and information security) are being created. digital technologies: distributed registries, social businesses, big data, sharing economics, the Internet of Things, open interfaces, wireless communications, etc. In particular, distributed registries based on blockchain technology are becoming quite widely spread on the financial markets of the country. This technology creates a new mechanism for human cooperation and can be considered as an enterprise, set up by man and willingly joined by people.

This is where certain problems occur. The matter is that traditionally the concept of "trust" implies the expectations of honest behavior on the part of the members of society, which is manifested in truthfulness, commitment to principles and liabilities taken, readiness to help according to the generally accepted norms and traditions of business practice.

The problem of trust in the time of market economy, whose exceptional quality is uncertainty, can hardly be solved simply by formal rules included in software.

In the opinion of American economists Herbert A. Simon and Kenneth Arrow, the institution of trust in deal-making acquires a special significance in the time of the lack of information, information asymmetry, etc., in the situations characterizing by information uncertainty. Considering the category of trust is no less important given that the market implies trust not only in information sources, information exchange, but also in the state, banks, exchanges, firms, and the market itself as an institution of market relations. [7,8]

An important contribution in solving the problem of trust has been made by a new institutional theory of economics (its representatives are Ronald Harry Coase, Douglass Cecil North, Oliver Eaton Williamson). From the institutionalists' point of view, trust should be reproduced by as many as possible institutions. Since trust is a multi-aspect phenomenon, it is manifested, in particular, in social media as a social institution and in other spheres of life of society. However, we would like to reduce this study to considering trust as an economic category. Social media play an increasingly important role in the sphere of interpersonal communications and economic life, but, still, this role is secondary in comparison to the market and political conditions. $[9,10,11]$

Among the factors making a negative impact on the institution of trust, are:

- excessive red tape and exaggerated focus on the legal aspect of an issue or phenomenon;

- creating a sophisticated monitoring system;

- class, ethnical, clan, and other barriers in society;

- lack of new organizational forms, ensuring reproduction of trust in the time when globalization and digitalization processes are developing in the economic life.

In our opinion, today there is need for an interrelation between trust and liability. Cooperation only in terms of formal rules, procedures and monitoring can generate a passive attitude towards complying with duties, indifference to 
the results of work, lack of initiative, irresponsibility; and, thus, labor becomes forced.

The same as any other modern information technology, blockchain technology implements the interaction of human and non-human subjects, constituting an integral whole. Smart contracts, which are also called self-executing or digital, transform the meaning of the concept of trust. Smart contracts, heralding a new type of contract relations, can push out traditional civil agreements. Since in many cases decentralized software packages, which set up a network, do not have their own or rented servers, it allows them to operate independently on many legal, economic and political institutions.

It is obvious that trust in financial operations using blockchain technology is not identified with the trust based on face-to-face interpersonal communication. It represents a technological principle analyzed by information technology and relies on joining voluntarily an agreement, which comprises of a program (cryptographic) code. A program code, to an extent, is assimilated to a legal act, guaranteeing confidentiality and genuine identification, and excluding nonauthorized access to the decentralized public database. Judging from Russian law, this type of agreement can be characterized as a conditional transaction or agreement, according to which the performance of obligations by one party is preconditioned by the performance of obligations by the other party.

In fact, trust in the blockchain system is a converted form of trust in decentralized technological systems, cryptographic algorithms, transactions, databases, etc., rather than trust in financial, judicial or other judicial persons. That is where a consensus should be reached between individual and collective identity, as well as the freedom-simulation idea should be realized. It has a limited nature because in case of technical failure, independently on its causes, the injured party is excluded from the agreement without being able to initiate negotiations or protect its rights in a court of law.

Experience suggests that errors in program code, attempts to rewrite a smart contract devaluate the algorithmic trust and value of the virtual collective freedom. A decentralized autonomous venture capital organization (foundation) set up on the basis of blockchain in 2016 through crowdfunding of $\$ 150$ million failed after two months because $\$ 55$ million was stolen by intruders via hacker attacks. It can be assumed that this practice hardly met up with the expectations of average users participating in the decentralized technological system which sold Ethereum cryptocurrency. To restore and consolidate algorithmic trust in the financial sphere, blockchain technology must be supplemented with the lacking attributes concerning security of transactions, protection of user data and consumer rights, protection from junk messaging, development of safe and reliable applications.

According to the International Telecommunication Union (ITU), Russia took the tenth place (out of 193 countries participating in the survey) by cyber security index, leaving behind such technologically developed countries as the UK, Japan, Norway, Germany, South Korea, Finland, etc. Financial organizations and commercial banks, as a rule, pay a lot of attention to the issues of security and trust in the information technology they use, since in the digital world, not only cybercrime can be a key threat to economic growth, but also result in losing clients and business. At the same time, interpersonal relationships in customer service remain to be important for keeping the customers' trust and, primarily, for making them sure that they are not going to lose a chance of dealing with the employees of a financial organization (bank) in person in case of need or emergency.

According to international threat intelligence security company Group-IB, more than $56 \%$ of ICO funds was stolen using phishing; in 2017 over $10 \%$ of all attracted investments was stolen, and $80 \%$ of projects failed to fulfill their obligations to the investors and disappeared after the money had been collected. [12]

As experience shows, in the cases when bitcoins are stolen and smart-contracts are used to commit crimes, blockchain agents responsible for these actions often get away with it because, frequently, they cannot be identified and their actions are outside the sphere of influence of law enforcement agencies. Liability is not assumed in a smart contract for noncompliance with it in case of natural disasters, death, etc., because these circumstances are not considered in this agreement. A smart contract is programmed in a way that it is impossible to avoid carrying it out or introduce any changes in it. In the end, there is a loss of the content of the notion of liability as one of the principles of civil relations, and it gets substituted for a technical (rather than civil) obligation in a form of programmed code.

From the position of traditional views, liability and the lack of liability can be equalized, the difference between what is legal and what is illegal gets disrupted, the same as the order the financial sphere relies on in its operations. Solving this problem is a very complicated task. If the state gets the rights for administering blockchain technology in a form of control over the contents of its registry and breaches the confidentiality of those participating in transactions, the basic principles of operation of this decentralized technology can be compromised in the financial sector. On the other hand, it could be reasonable to differentiate between smart contracts and civil law contracts. In this way it should be defined that any participant in blockchain (a creator of blocks, a miner, a financial regulator, a central bank or any other person) who comes into a smart contract and becomes a subject of anonymous collective identity should be the one to pay for the risks involved. [13, 14]

Of course, some steps are taken into this direction. In particular, Blockchain 3.0 (Precedent) project implies including the elements of legal regulation. [15] This regulation is decentralized and implies registering disputes that are settled by a peering method. Having the interests of the Precedent community in mind, as a rule, miners decide if the protocol can be changed in case it does not meet new financial and economic conditions. At the same time, it is guaranteed that the enquiry recorded in the protocol will be considered, but the miners can lack the technical capability to ensure unconditional responsibility of the disclosed offenders. Moreover, miners themselves can be abusive since they can be economically interested or not very well educated in law. So it 


\section{References}

becomes objectively necessary that specific legal standards be introduced in the program code and adapted to the technical requirements of information technology.

\section{CONCLUSION}

In the analysis of multipurpose impact of digitalization on the socioeconomic relations in society and the global economy, it has been found out that there is a diversity of scientific approaches to understanding the concept of "trust" and "liability". Until recently there have been active discussions of the issues related to creating a new mechanism for human relationships in the socioeconomic sphere, setting up new institutions and reforming the traditional ones to regulate the processes of digitalization, the activity of new technological players given their integration into the socioeconomic system of society. There is need for researching the profound changes that occur in the socioeconomic system of the developing information society and concern not only to business relationships, but also relation to social institutions, interpersonal relationships, etc. Considering digitalization as an institutional technology makes it possible to find out the drawbacks and contradictions, influencing the achievement of trust in decentralized technological systems and the acceptance of liability for complying with an agreement which represents a program (cryptographic) code. It also helps to determine the ways to overcome these drawbacks and contradictions. It has emerged that nowadays it is increasingly important to restore and consolidate algorithmic trust in financial and other spheres of public life, and increase liability in a smart contract, which are some of the most important elements of civil relations.
[1] J. Mittelman, "Rethinking the new regionalism", Global Governance, no. 2, pp.189-213, 1996.

[2] A. Ulezko and M. Zhukova, "Digitalization as a stage in the evolution of socioeconomic systems", The Bulletin of the Voronezh State Agricultural University, no. 1 (60), pp. 169-179, 2019.

[3] K. Schwab, The Fourth Industrial Revolution. EXPO, Moscow, 2016.

[4] M.R. Wade, "The Digital Vortex in 2017: It's not a question of "when", 2017 [Electronic resource]. Available at: https://www.imd.org/dbt/articles/digital-vortex-in-2017.

[5] V.G. Khalin and G.V. Chernova, "Digitalization and its impact on the Russian economy and society: advantages, challenges, threats and risks", Management Consulting, no. 10, pp. 46-63, 2018.

[6] M. Miroshnichenko and G. Chudesova, "Digital economy as a promising mechanism for development", Journal Economics and Environmental Management, no. 2 (37), pp. 121-129, 2019.

[7] G. Simon, "Rationality as Process and as Product of Thought", THESIS: theory and history of economic and social institutions and systems, vol. 3, pp. 16-38, 1993.

[8] K. Arroy, "Risk perception in psychology and economics", THESIS: theory and history of economic and social institutions and systems, vol. 5, pp. 81-90, 1994.

[9] O. Williamson, The economic institutions of capitalism. Firms, markets, relational contracting, Lenizdat, CEV Press, Saint Petersburg, $\mathrm{SPb}, 1996$.

[10] R. Coase, The Firm, the Market, and the Law: collection of papers. Novoye Izdatelstvo, Moscow, 2007.

[11] D. North, "Institutions, Institutional Change and Economic Performance", Voprosy Ekonomiki, no. 3, pp. 6-17, 1997.

[12] The website of the international cybersecurity firm Group-IB, 2019 [Electronic resource]. Available at: https://www.group-ib.ru/media/gibcrypto-summary/.

[13] N. Richards and J. King, "Big data ethics", Wake Forest jaw review, Winston-Salem, vol. 49, no. 2, pp. 393-432, 2014.

[14] D. Filippov, "The influence of financial technologies on the development of the financial market", Russian Entrepreneurship, vol. 19, no. 5, pp. 1437-1464, 2018.

[15] M. Swan, Blockchain: Blueprint for a New Economy. Publisher "Olymp-Business", Moscow, 2017. 